\title{
Involvement of the Intracellular Ion Channel CLIC1 in Microglia-Mediated $\beta$-Amyloid-Induced Neurotoxicity
}

\author{
Gaia Novarino, ${ }^{1 \star}$ Cinzia Fabrizi, ${ }^{2 *}$ Raffaella Tonini, ${ }^{1 *}$ Michela A. Denti, ${ }^{3}$ Fiorella Malchiodi-Albedi, ${ }^{5}$ \\ Giuliana M. Lauro, ${ }^{4}$ Benedetto Sacchetti, ${ }^{5}$ Silvia Paradisi, ${ }^{5}$ Arnaldo Ferroni, ${ }^{6}$ Paul M. Curmi, ${ }^{7}$ Samuel N. Breit, ${ }^{8}$ and \\ Michele Mazzanti ${ }^{1}$ \\ Dipartimenti di ${ }^{1}$ Biologia Cellulare e dello Sviluppo, ${ }^{2}$ Scienze Cardiovascolari e Respiratorie, and ${ }^{3}$ Genetica e Biologia Molecolare, Università “La Sapienza”, \\ 00185 Rome, Italy, ${ }^{4}$ Dipartimento di Biologia, Università "Roma Tre”, 00154 Rome, Italy, ${ }^{5}$ Dipartimento di Biologia Cellulare e Neuroscienze, Istituto \\ Superiore di Sanità, 00185 Rome, Italy, ${ }^{6}$ Dipartimento di Scienze Biomolecolari e Biotecnologie, 20133 Milan, Italy, ${ }^{7}$ Initiative for Biomolecular Structure, \\ School of Physics, University of New South Wales, Sydney 2052, Australia, and ${ }^{8}$ Centre for Immunology, St Vincent's Hospital and University of New South \\ Wales, Sydney 2010, Australia
}

It is widely believed that the inflammatory events mediated by microglial activation contribute to several neurodegenerative processes. Alzheimer's disease, for example, is characterized by an accumulation of $\beta$-amyloid protein $(\mathrm{A} \beta)$ in neuritic plaques that are infiltrated by reactive microglia and astrocytes. Although $\mathrm{A} \beta$ and its fragment 25-35 exert a direct toxic effect on neurons, they also activate microglia. Microglial activation is accompanied by morphological changes, cell proliferation, and release of various cytokines and growth factors. A number of scientific reports suggest that the increased proliferation of microglial cells is dependent on ionic membrane currents and in particular on chloride conductances. An unusual chloride ion channel known to be associated with macrophage activation is the chloride intracellular channel-1 (CLIC1). Here we show that $\mathrm{A} \beta$ stimulation of neonatal rat microglia specifically leads to the increase in CLIC1 protein and to the functional expression of CLIC1 chloride conductance, both barely detectable on the plasma membrane of quiescent cells. CLIC1 protein expression in microglia increases after $24 \mathrm{hr}$ of incubation with $\mathrm{A} \beta$, simultaneously with the production of reactive nitrogen intermediates and of tumor necrosis factor- $\alpha$ (TNF- $\alpha$ ). We demonstrate that reducing CLIC1 chloride conductance by a specific blocker [IAA-94 $(R(+)$-[ (6,7-dichloro-2-cyclopentyl-2,3-dihydro-2-methyl-1-oxo-1H-inden-5yl)-oxy] acetic acid)] prevents neuronal apoptosis in neurons cocultured with $\mathrm{A} \beta$-treated microglia. Furthermore, we show that small interfering RNAs used to knock down CLIC1 expression prevent TNF- $\alpha$ release induced by A $\beta$ stimulation. These results provide a direct link between $\mathrm{A} \beta$-induced microglial activation and CLIC1 functional expression.

Key words: Alzheimer; microglia; neurotoxicity; CLIC1; chloride channel; $\beta$-amyloid

\section{Introduction}

Chloride intracellular channel-1 (CLIC1) was originally cloned from a human myelomonocytic cell line (U937) (Valenzuela et al., 1997). It is localized to both the nucleoplasm and cytosol and exhibits both nuclear and plasma membrane chloride channel activity. In particular, we demonstrated previously that, in Chinese hamster ovary CHO cells, CLIC1 channel activity is found on the plasma membrane of cells in the act of dividing or that have just divided (Tonini et al., 2000; Valenzuela et al., 2000). Additionally, it has been reported that CLIC1 expression is re-

\footnotetext{
Received 0ct. 23, 2003; revised April 21, 2004; accepted April 22, 2004.

This work was supported by a grant from Ministero dell'Istruzione, dell'Università, e della Ricerca (M.M.), by the Italian Ministry of Health, Department of Social Service Grant RF99.38 (G.M.L.), by Fondo per gli Investimenti della Ricerca di Base Grants RBNE01KXC9 and RBNE015MPB, by an intramural grant from Università Roma 1 "La Sapienza" (M.M.), and by the Alzheimer Project, Italian Ministry of Health (F.M.-A.). We thank Stefania Catino for excellent technical support and Renata Zippel for critical reading of this manuscript. We are also indebted to Prof. Irene Bozzoni for active support.

${ }^{*}$ G.N., C.F., and R.T. contributed equally to this work.

Correspondence should be addressed to Michele Mazzanti, Università La Sapienza, Biologia Cellulare e dello Sviluppo, Piazzale Aldo Moro 5, 00185 Rome, Italy. E-mail: michele.mazzanti@uniroma1.it.

D0I:10.1523/JNEUROSCI.1170-04.2004

Copyright $\odot 2004$ Society for Neuroscience $\quad$ 0270-6474/04/245322-09\$15.00/0
}

lated to macrophage activation in U937 cells in which CLIC1 mRNA is upregulated by various activation stimuli, including phorbol-12-myristate-13 acetate (PMA). This regulation was also found to be associated with the maturational state of the cell because the response to PMA is enhanced by a previous exposure to retinoic acid. This linkage of CLIC1 expression with macrophage activation has prompted us to examine both the expression and role of CLIC1 in microglial cells (the brain macrophages).

It has been reported that the inflammatory events mediated by microglial activation contribute to several neurodegenerative processes, including Alzheimer's disease (AD) (McGeer et al., 1993, 1994; McGeer and McGeer, 1997, 1998; Kalaria, 1999). The $\mathrm{AD}$ brain is characterized by selective neuronal loss, neurofibrillary tangles, and abundant extracellular deposits of insoluble $\beta$-amyloid protein $(\mathrm{A} \beta)$ (Glenner and Wong, 1984). In particular, the senile plaques of $\mathrm{AD}$ are sites of inflammatory processes, as evidenced by the presence of reactive microglia and astrocytes associated with the plaques (Itagaki et al., 1989). It is possible that activation of microglial cells leads to the production of various cytokines and neurotoxins, which may ultimately cause neuronal injury and death (Barger and Harmon, 1997; Egensperger et al., 
1998; Styren et al., 1998; Benveniste et al., 2001; Combs et al., 2001).

In vitro treatment with $\mathrm{A} \beta$ or $\mathrm{A} \beta$ fragments results in proliferation of microglia and release of inflammatory cytokines and reactive nitrogen intermediates (Araujo and Cotman, 1992; Meda et al., 1995; Casal et al., 2002). The biologically active region of $\mathrm{A} \beta$ is restricted to amino acids $25-35$ at the $\mathrm{C}$ terminus (Yankner et al., 1990), and an $\mathrm{A} \beta_{25-35}$ amyloid peptide is sufficient to stimulate intracellular signaling cascades in microglial cells. This occurs by initiating mechanisms common to the $1-40$ and $1-42 \mathrm{~A} \beta$ peptides.

In the present study, we provide evidences that microglial cells express CLIC1 protein. Activation of microglia by $\mathrm{A} \beta$ peptides results in an overall increase in CLIC1 protein with resultant increase in CLIC1 ion channel activity. A specific CLIC1 blocker [IAA-94 $(R(+)$ - $[$ (6,7-dichloro-2-cyclopentyl-2,3-dihydro-2methyl-1-oxo-1H-inden-5yl)-oxy] acetic acid)] acts broadly to inhibit the production of proinflammatory and neurotoxic products elaborated by $\mathrm{A} \beta$-stimulated microglial cells and functions as a neuroprotective agent in neuronal-microglial cocultures. However, when CLIC1 expression is knocked down by small interfering RNAs (siRNAs), the $\mathrm{A} \beta$-induced production of tumor necrosis factor- $\alpha$ (TNF- $\alpha$ ) in microglia is completely prevented.

\section{Materials and Methods}

Cell cultures. The CLIC1-transfected CHO cells (Cl4) (Tonini et al., 2000) and the murine microglial cell line BV-2 were grown in DMEM (Invitrogen, Milan, Italy) supplemented with $10 \%$ fetal calf serum (FCS) (Sigma, Milan, Italy) in $5 \% \mathrm{CO}_{2}$. Primary microglial cell cultures were derived from postnatal day 3-4 rat cortex as described previously (Bezzi et al., 1998). Free-floating microglia were collected from shaken astrocytes flasks and seeded onto standard flasks or 24-well plates, with four paraffin drops on the bottom (see below), and maintained in DMEM supplemented with $10 \% \mathrm{FCS}$ in $5 \% \mathrm{CO}_{2}$. The purity of microglial cultures was assessed by a positive staining for Griffonia Simplicifolia isolectin B4 (Vector Laboratories Burlingame, CA), a selective marker of both resting and activated microglia. Cortical neurons were cultured from postnatal day $0-1$ rat cortex. Meninges-free cortices were isolated and digested in HIBERNATE-A media (BrainBits, Springfield, IL) supplemented with B27 (Invitrogen) and $0.5 \mathrm{~mm}$ glutamine (Sigma) for $20 \mathrm{~min}$ at $30^{\circ} \mathrm{C}$. Cortices were transferred to Neurobasal-A/B27 (NBA/B27) medium (Invitrogen), triturated, and plated onto poly-L-lysine $(0.01 \mathrm{mg} / \mathrm{ml})$-coated tissue culture wells. Neurons were grown in NBA/B27 for $5 \mathrm{~d}$ in vitro before the experiment. The use of NBA/B27 provided highly purified cultures of neurons to decrease the contamination of glial cells in the cultures (Brewer et al., 1993). Mixed neuronal-microglial cell cultures were prepared by adding $5 \times 10^{4}$ microglial cells to cortical neuronal cultures.

In a separate set of experiments, primary hippocampal neurons were prepared from embryonic day 18 rat brain (Goslin and Banker, 1990). After dissection, the hippocampi were treated with $2.5 \%$ trypsin and dissociated with a flame-polished Pasteur pipette. The cells were plated onto poly-L-lysine-treated glass coverslips in Minimum Essential Medium (Invitrogen), containing 10\% FCS. After $2 \mathrm{hr}$, the medium was substituted with NBA/B27. After $8 \mathrm{hr}$ from seeding, $5 \mu \mathrm{M}$ arabinosylcytosine was added. Neuronal cell cultures contained $<1 \%$ of astrocytes, as shown by glial fibrillary acidic protein staining (data not shown). For neuronal-microglial cocultures, after $1 \mathrm{~d}$ in vitro, coverslips were transferred to the 24-well plates containing the microglial cells, facing down, on top of the paraffin drops, which maintained the coverslips distant from the microglial monolayer. In this way, neurons were conditioned by the microglia, sharing the same medium, but were not in direct contact with the microglial cells.

Cell stimulation. BV-2 and primary microglial cells were treated with $\mathrm{A} \beta_{1-42}, \mathrm{~A} \beta_{25-35}$, and $\mathrm{A} \beta_{35-25}$ (reverse) peptides (Bachem, Bubendorf, Switzerland), basic FGF (bFGF) (Sigma), Escherichia coli lipopolysaccharide
(LPS) (serotype 0127:B8; Sigma), $R(+$ )-[ (6,7-dichloro-2-cyclopentyl-2,3dihydro-2-methyl-1-oxo-1H-inden-5yl)-oxy] acetic acid (IAA-94) (Biomol, Plymouth Meeting, PA), and niflumic acid (Sigma).

$\mathrm{A} \beta_{25-35}$ and $\mathrm{A} \beta_{35-25}$ (reverse) peptides were dissolved in sterile, distilled water at a concentration of $1 \mathrm{~mm}$ and incubated for $72 \mathrm{hr}$ at $37^{\circ} \mathrm{C}$ to allow aggregation. The reverse peptide was used as a control. $\mathrm{A} \beta_{1-42}$ was dissolved in sterile water to $1 \mathrm{~mm}$ and incubated at $37^{\circ} \mathrm{C}$ for $7 \mathrm{~d}$.

For coculturing experiments, $\mathrm{A} \beta_{25-35}$ or the reverse peptide were added to the 24-well plates containing the microglial cultures. Six hours later, coverslips with the seeded neurons were transferred to the wells containing the microglial cells, facing down, on top of the paraffin drops. As reported previously, this procedure permits sedimentation of $A \beta$ aggregates to the bottom of the well and minimizes the interaction of $A \beta$ with neurons (Malchiodi-Albedi et al., 2001).

Western blot. SDS-PAGE and Western blotting were performed by standard techniques. Briefly, cells were lysed on ice in $50 \mathrm{~mm}$ Tris- $\mathrm{HCl}$, pH 7.0, 0.5\% NP-40, 2 mm AEBSF [4-(2-aminomethyl)benzenesulfonylfluoride hydrochloride], $2 \mu \mathrm{M}$ aprotinin, $40 \mu \mathrm{M}$ leupeptin, $70 \mu \mathrm{M}$ bestatin, $30 \mu \mathrm{M}$ pepstatin $\mathrm{A}$, and $30 \mu \mathrm{M}$ E-64 [trans-epoxysuccinyl-1leucylamido-(4-guanidino)-butane]. Samples were clarified by centrifugation at $1000 \times g$ for $5 \mathrm{~min}$. Equivalent amounts of proteins $(30 \mu \mathrm{g})$ were subjected to SDS-PAGE by using $12 \%$ polyacrylamide gels, and proteins were electroblotted to nitrocellulose. The membranes were blocked with $3 \%$ bovine serum albumin (BSA) in PBS for $1 \mathrm{hr}$ and then incubated overnight at $4^{\circ} \mathrm{C}$ with anti-NCC27 (1:8000) (Valenzuela et al., $1997)$ or with anti- $\beta$-tubulin (1:7000; ICN Pharmaceuticals, Milan, Italy) in PBS containing $0.1 \%$ Tween 20 and 3\% BSA. After extensive washing, a peroxidase-conjugated anti-rabbit (or anti-mouse) antibody diluted in PBS containing $0.1 \%$ Tween 20 was added for $1 \mathrm{hr}$. Antibody binding was detected by chemiluminescence kit (ECL Blotting System; Amersham Biosciences, Milan, Italy).

Cell surface protein biotinylation. $\mathrm{Cl} 4$ and BV-2 cells were plated $(1 \times$ $10^{6}$ cells per well) onto poly-L-lysine-coated $60 \mathrm{~mm}$ Petri dishes $12 \mathrm{hr}$ before stimulation. Cells were stimulated with $30 \mu \mathrm{MA} \beta_{25-35}$ or 100 $\mathrm{ng} / \mathrm{ml}$ bFGF. After $48 \mathrm{hr}$ from stimulation, medium was removed and the cells were washed three times with cold PBS, $\mathrm{pH} 7.3$, containing $1 \mathrm{~mm}$ $\mathrm{MgCl}_{2}$ and $0.1 \mathrm{~mm} \mathrm{CaCl}{ }_{2},\left(\mathrm{PBS} / \mathrm{Ca}^{2+} / \mathrm{Mg}^{2+}\right)$. Cell surface biotinylation was performed as described previously (Apparsundaram et al., 1998). Cells were incubated for $30 \mathrm{~min}$ at $4{ }^{\circ} \mathrm{C}$ in $\mathrm{PBS} / \mathrm{Ca}^{2+} / \mathrm{Mg}^{2+}$ containing $1.5 \mathrm{mg} / \mathrm{ml} \mathrm{EZ-Link} \mathrm{Sulfo-NHS-Biotin} \mathrm{(Pierce,} \mathrm{Rockford,} \mathrm{IL).} \mathrm{Unless}$ stated otherwise, all of the remaining steps were performed at $4^{\circ} \mathrm{C}$. The biotinylation reagent was removed, and the cells were washed twice with $\mathrm{PBS} / \mathrm{Ca}^{2+} / \mathrm{Mg}^{2+}$ containing $100 \mathrm{~mm}$ glycine, followed by quenching for 30 min with the same reagent and one additional wash with $0.5 \mathrm{~mm}$ PMSF in PBS. Cells in each plate were gently shaken in $400 \mu \mathrm{l}$ of lysis buffer [PBS, $1 \%$ Triton X-100, and protease inhibitor mixture (Sigma)] for $1 \mathrm{hr}$. Cell lysates were centrifuged $(20,000 \times g$ for $30 \mathrm{~min})$, and the protein concentration of each lysate was determined. Twenty micrograms of each sample were removed (total lysate), and $350 \mu \mathrm{g}$ were incubated with monomeric avidin beads (Pierce). Before use, monomeric avidin was washed in lysis buffer. The avidin beads were mixed with cell lysate by rotation for $1 \mathrm{hr}$ at room temperature (RT). Unbound proteins were separated by centrifugation $(15,000 \times g$ for $3 \mathrm{~min}$ at RT), and $20 \mu \mathrm{g}$ for each sample were taken (intracellular fraction). The beads were washed three times with lysis buffer and eluted with Laemmli loading buffer (surface fraction). Samples were subjected to electrophoresis by using $15 \%$ SDS-polyacrylamide gels, and Western blot was performed.

Patch-clamp recordings. The patch electrodes were pulled from hard borosilicate glass on a Brown-Flaming P-87 puller (Sutter Instruments, Novato, CA). The pipettes were coated with Sylgard (Dow Corning) and fire polished to an external tip diameter of $1-1.5 \mu \mathrm{m}$. These electrodes had resistances of 7-10 M $\Omega$. We applied standard cell-attached patchclamp techniques to obtain seals of $20-50 \mathrm{G} \Omega$ in the single-channel recordings. Analytical grade reagents were purchased from Sigma. The bath solution contained the following (in mM): $140 \mathrm{NaCl}, 5 \mathrm{KCl}, 1 \mathrm{MgCl}_{2}$, $2.5 \mathrm{CaCl}_{2}, 10$ HEPES, and 10 glucose, $\mathrm{pH}$ 7.3. The pipette solution contained the following (in $\mathrm{mm}$ ): $127.5 \mathrm{~N}$-methyl-glucamine-Cl, $5 \mathrm{KCl}, 2.5$ $\mathrm{CaCl}_{2}, 1 \mathrm{MgCl}_{2}, 10 \mathrm{HEPES}, 10$ glucose, 10 tetraethylammonium-Cl, 5 4-aminopyridine, and 0.03 margatoxin, $\mathrm{pH}$ 7.3. In the experiments to 
determine the $\mathrm{Cl}$ dependence of CLIC1 currents, the chloride anion were replaced as a counter ion of $N$-methyl-glucamine by methansulfonate to obtained a final $\mathrm{Cl}$ concentration of 60 or $30 \mathrm{~mm}$. We calculated the junction potential (JP) using pClamp routine (Axon Instruments, Foster City, CA). For 149.5, 60, and $30 \mathrm{~mm}$ chloride concentration solutions, the JPs were $-5,-0.7$, and +0.6 , respectively. Experimental points were not corrected for these JPs. For outside-out experiments, the patch electrode contained the following (in $\mathrm{mm}$ ): 10 $\mathrm{NaCl}, 130 \mathrm{~K}$-Asp, $2 \mathrm{MgCl}_{2}, 1.3 \mathrm{CaCl}_{2}, 10$ HEPES, and 10 EGTA, pH 7.3.

Single-channel currents were recorded with an Axon Instruments 200B patch-clamp amplifier and digitized by Clampex 8 routine (pClamp 8; Axon Instruments). Single-channel currents were filtered at $1 \mathrm{kHz}$, sampled at 10 $\mathrm{kHz}$, and analyzed by Fetchan routine (pClamp 6; Axon Instruments). Opening and closing transitions were detected using a 50\% threshold criterion. Kinetic parameters have to be regarded as "apparent" because of the effects of unresolved shuttings and openings. Total channel open probability $\left(N P_{\mathrm{o}}\right)$ was calculated as the total open time during a recording divided by the whole-record duration. Open time distributions were fitted with single-exponential function using the least-squares method.

Growth curves. BV-2 cells and primary microglial cells were plated ( $5000 \mathrm{cells} / \mathrm{cm}^{2}$ ) onto $35 \mathrm{~mm}$ Petri dishes $12 \mathrm{hr}$ before stimulation. Stimulation was performed by using $30 \mu \mathrm{M} \mathrm{A} \beta_{25-35}$ or $100 \mathrm{ng} / \mathrm{ml}$ bFGF. IAA-94 at $30 \mu \mathrm{M}$ was added together with $\mathrm{A} \beta$ or bFGF. After 24 and $48 \mathrm{hr}$ of treatment, cells were detached with trypsin and counted.

Viability assay. Viable cells were determined by uptake and hydrolysis of fluorescein diacetate (Brewer et al., 1993). Briefly, mixed cultures of cortical neuronal cells and primary microglia were rinsed twice with HBSS (Invitrogen) and treated with fluorescein diacetate $(15 \mu \mathrm{g} / \mathrm{ml}$; Sigma) and propidium iodide ( $4.6 \mu \mathrm{g} / \mathrm{ml}$; Sigma). With blue excitation, live cells fluoresce green, and dead cell fluoresce red. For statistical analysis, at least 12 consecutive $0.313 \mathrm{~mm}^{2}(20 \times)$ fields were counted for each sample. The experiment was repeated four times with similar results, but data were not combined for statistical analysis because of variations of plating efficiency.

Terminal deoxynucleotidyl transferase-mediated biotinylated UTP nick end labeling assay. Neurons cocultivated with microglia were fixed in 3\% paraformaldehyde in PBS and $0.2 \mathrm{M}$ in sucrose and were treated with the terminal deoxynucleotidyl transferase-mediated biotinylated UTP nick end labeling (TUNEL) technique, using the DeadEnd kit (Promega, Madison, WI). TUNEL-positive cells were counted at a Nikon (Tokyo, Japan) Optiphot microscope. Eight microscopic fields were chosen randomly by two separate observers for a total of at least 300 cells for each coverslip. Two coverslips were scored for each condition. The percentage of apoptotic cells was calculated as the number of TUNEL-positive cells divided by the total cell number. The values obtained for each coverslip by the two observers were averaged to produce a single mean value for each experiment. The experiment was repeated three times, using three different neuronal and microglial cell culture preparations.

Tumor necrosis factor- $\alpha$ and nitrite release. The release of TNF- $\alpha$ into culture supernatants was determined by standard ELISA techniques according to the instructions of the manufacturer ( $R$ \& D Systems, Minneapolis, $\mathrm{MN})$.

Nitrite $\left(\mathrm{NO}_{2}{ }^{-}\right)$was determined by using the Griess reagent (1 mM sulfanilamide, $1 \mathrm{~mm}$ naphthylenediamine dihydrochloride, and $100 \mathrm{~mm}$ $\mathrm{HCl})$ in culture supernatants. Absorbance was measured at $540 \mathrm{~nm}$, and $\mathrm{NO}_{2}{ }^{-}$concentration was determined using sodium nitrite as a standard.

RNA interference. The psiUb-cliclA and psiUb-clic1B RNA interference (RNAi) constructs were designed as described by M. Denti (unpublished observation). Briefly, 21-nucleotide-long inverted repeats, separated by a nine nucleotide linker, were inserted downstream of the U1 promoter by cloning two pairs of annealed oligonucleotides in the BglII and XhoI sites of vector psiUx (Denti, unpublished observation). The transcribed RNAs thus comprised 24 bp hairpin RNAs, together with a terminal stem-bulge structure. The $3^{\prime}$ terminus is produced by a conserved box element inserted downstream of the antisense strand. The sense strand of the short hairpins was homologous to 21 nucleotide regions in the target CLIC1 mRNA and contained at least four nucleotide mismatches with all other murine genes, as determined by BLAST (basic local alignment search tool) searches. The sense strand of psiUb-clic1A construct was designed to be homologous to a region located in the fifth exon of CLIC1 mRNA (nucleotides 862-882 in sequence BC004658). The psiUb-clic1B construct was designed to target exon 6 of CLIC1 mRNA (nucleotides 1068-1088 of sequence BC004658). psiUbclic1C and psiUb-clic1D target region 712-732 and region 926-946 of CLIC1 mRNA (sequence BC004658), respectively.

BV-2 calls at $90 \%$ confluence were transfected with $4 \mu \mathrm{g}$ of plasmid in $35 \mathrm{~mm}$ plates using Lipofectamine 2000 (Invitrogen) according to the instructions of the manufacturer.

After $48 \mathrm{hr}$ from transfection, with the control vector (psiUx), psiUbclic1A, psiUb-clic1B, psiUb-clic1C, or psiUb-clic1D, BV-2 cells were treated for $24 \mathrm{hr}$ with $30 \mu \mathrm{M} \mathrm{A} \beta_{25-35}$, and the release of TNF- $\alpha$ in the medium was measured by standard ELISA.

\section{Results}

\section{$\mathrm{A} \boldsymbol{\beta}$ treatment increases CLIC1 protein expression in microglial cells}

In freshly dissociated neonatal rat microglial cells, as well as in the microglial cell line BV-2, immunoblot analysis of whole-cell lysates demonstrated a $27 \mathrm{kDa}$ protein corresponding to CLIC1 (Fig. 1a). Because previous results demonstrated CLIC1 mRNA to be upregulated during PMA-induced macrophage activation, we tested its expression in microglial cells activated by different stimuli, including $\mathrm{A} \beta_{1-42}, \mathrm{~A} \beta_{25-35}$, LPS, and bFGF. In previous experiments, we determined the lowest concentrations of $\mathrm{A} \beta$ peptides required in our experimental conditions for microglial activation, as revealed by increased TNF- $\alpha$ release. They correspond to $20 \mu \mathrm{MA} \beta_{1-42}$ and $30 \mu \mathrm{M} \mathrm{A} \beta_{25-35}$.

As determined by densitometric analysis, both $\mathrm{A} \beta_{1-42}$ and $\mathrm{A} \beta_{25-35}$ treatments resulted in an increased expression of CLIC1 by approximately twofold in BV-2 cells after $48 \mathrm{hr}$ (Fig. 1b,d). In contrast, LPS was unable to modify CLIC1 expression, consistent with previous data obtained in U937 cells (Valenzuela et al., 
$\mathbf{a}$
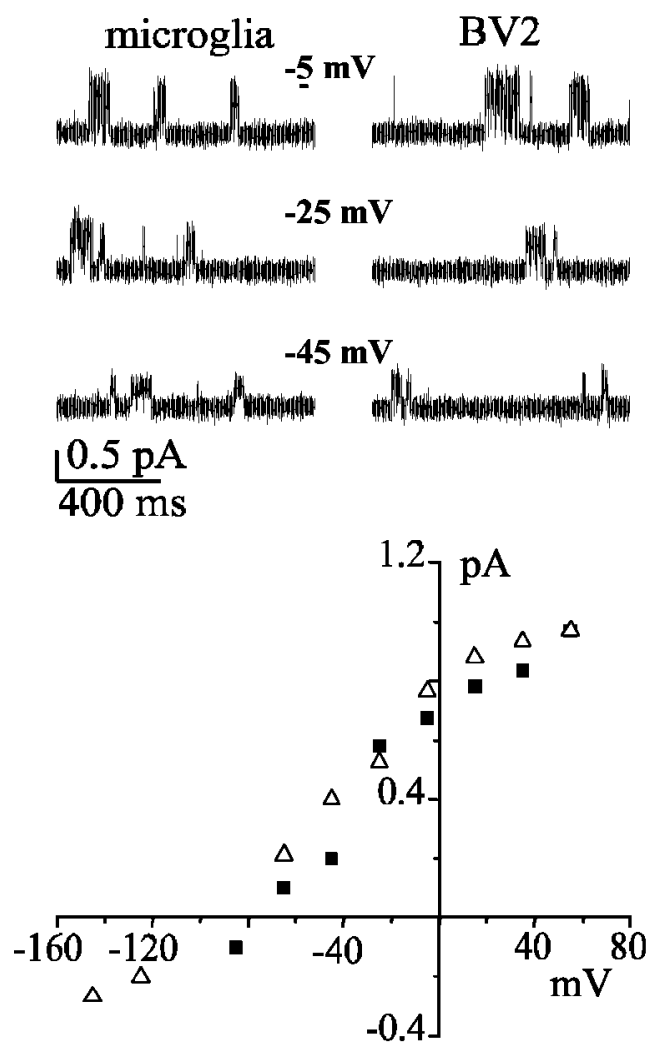

b
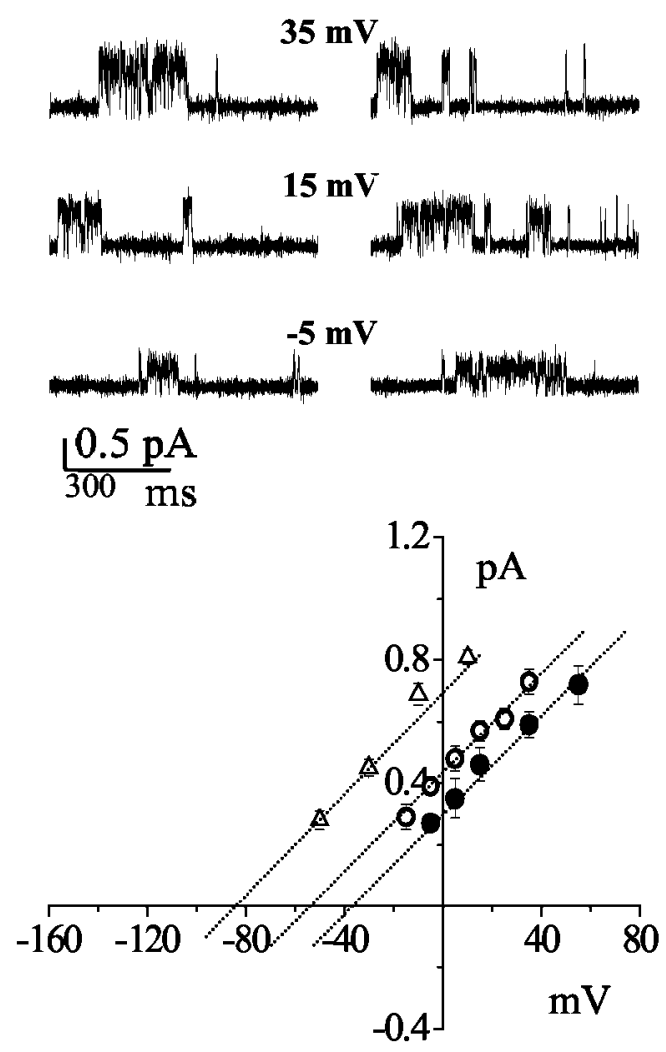

Figure 2. Comparison of CLIC1 single-channel properties in primary rat microglia and in the BV-2 cell line. $a$, Single-channel current traces recorded at different membrane potentials from
1997). Also, bFGF was unable to modify the expression of CLIC1 on primary rat microglia (Fig. 1c), as well as in BV-2 cells (Fig. $1 d)$. In rat primary microglial cells, the increased expression of CLIC1 protein was observed at 24 and $48 \mathrm{hr}$ of treatment with $\mathrm{A} \beta_{25-35}$, and it corresponded to an increment of twofold and threefold, respectively (Fig. 1e). The substantial agreement in the results obtained using $\mathrm{A} \beta_{1-42}$ or $\mathrm{A} \beta_{25-35}$ allowed us to use, from now on, the short peptide in following experiments.

Activating microglial cells increases CLIC1 protein localized to the plasma membrane

To determine whether increased amounts of CLIC1 protein were expressed on the plasma membrane in association with microglial activation, we used cell surface biotinylation. Both BV-2 cells stimulated for $48 \mathrm{hr}$ with $\mathrm{A} \beta$ and bFGF and untreated control cells were incubated with membrane-impermeable activated biotin. This caused the biotin labeling only of proteins present on the cell surface. The biotinylated proteins were then isolated with monomeric avidin beads and subjected to electrophoresis and Western blotting. CLIC1 was present on the cell surface of BV-2 cells in virtually all of the preparations, but higher levels were detected in $\mathrm{A} \beta_{25-35}$-treated samples (Fig. 1f). This result indicates that $\mathrm{A} \beta$-induced microglial activation, together with an overall increase in CLIC1 protein expression, is also associated with a higher level of CLIC1 on the plasma membrane.

\section{Microglial cell plasma membranes display ionic conductances characteristic of CLIC1}

CLIC1 single-channel currents from rat microglial cells and from the BV-2 cell line were systematically recorded using the cellattached patch-clamp technique. Figure $2 a$ shows sample current recordings in these two cell types at different membrane potentials. The mean open time $\left(\tau_{\mathrm{o}}=4.2 \pm 0.12\right.$ and $\left.4.5 \pm 0.3 \mathrm{msec}\right)$ and open probability $\left(P_{\mathrm{o}}=0.24 \pm 0.6\right.$ and $\left.0.27 \pm 0.4\right)$ at $-5 \mathrm{mV}$ of membrane potential for microglial primary cultures and microglial cell line (BV-2) matched the kinetic parameters measured in CLIC1-transfected CHO cells (Tonini et al., 2000; Valenzuela et al., 2000). The values of single-channel conductances were $7.14 \pm 0.03$ and $6.39 \pm 0.018 \mathrm{pS}$, and the current reversal potential was -81 and $-85 \mathrm{mV}$ for rat microglia and for BV-2 cells, respectively. There is a complete agreement in the conductance values calculated from the current-voltage $(I-V)$ plot $(c)$ and previous CLIC1 conductance measurements that we undertook in CLIC1-transfected CHO cells (Tonini et al., 2000; Valenzuela et al., 2000). In Figure $2 b$, we show single-channel current recordings obtained from $\mathrm{BV}-2$ cells in cell-attached configuration using 60 and $30 \mathrm{~mm} \mathrm{Cl}$ solution in the patch pipette. The current-voltage relationship on the bottom shows that the conductances in these cases are $6.27 \pm 0.032$ and $6.05 \pm 0.054 \mathrm{pS}$, and the mean open times are $4.3 \pm 0.23$ and $4.7 \pm 0.41 \mathrm{msec}$, respectively. The extrapolated reversal potentials are -58 and -38 $\mathrm{mV}$ at 60 and $30 \mathrm{~mm} \mathrm{Cl}$ according to a chloride dependence of the channel current. For comparison, we report in the same plot four single-channel current values obtained in BV-2 cells in the same

primary microglia (top left) and BV-2 cells (top right). The $I-V$ relationship derived from 5000 msec of data at each potential from microglia $(\square)$ and BV-2 cells $(\triangle)$ is shown on the bottom. In $b$, we show current recordings from BV-2 cells using 60 (top left) and 30 (top right) $\mathrm{mM}$ chloride in the cell-attached pipette. The three dotted lines are (from left to right) the linear fit of single-channel current amplitudes obtained from $2000 \mathrm{msec}$ of data at different membrane voltages using $149.5(\triangle), 60(\bigcirc)$, and $30(\bigcirc) \mathrm{mm}$ chloride in the cell-attached pipette. Error bars have been omitted when smaller than symbols. 
condition as in Figure $2 a$. In this case, with $149.5 \mathrm{Cl}$ in the pipette solution, the reversal potential was $-83 \mathrm{mV}$.

Microglial activation by $\mathbf{A} \boldsymbol{\beta}_{25-35}$ increases the open probability for CLIC1 conductance on the plasma membrane

$\mathrm{A} \beta_{25-35}$ stimulation of microglial cells led to a significant increase in both singlechannel open probability $\left(N P_{\mathrm{o}}\right)$ and mean open duration $\left(\tau_{\mathrm{o}}\right)$ without changes in the channel conductance value. Figure $3 a$ presents data from cell-attached experiments on BV-2 cells before and after 24 hr activation with $\mathrm{A} \beta_{25-35}$. At a membrane potential of $+20 \mathrm{mV}, N P_{\mathrm{o}}$ changed from $0.22 \pm$ 0.08 to $0.48 \pm 0.11(n=6 ; p<0.05)$, and the mean open time increased from $4.9 \pm$ 0.87 to $12.7 \pm 2.76 \mathrm{msec}(n=6 ; p<0.05)$, with a distribution made of a singleexponential component (Fig. 3b). Figure $3 c$ depicts the action of $10 \mu \mathrm{M}$ IAA-94, a specific CLIC1 blocker, acting on both control and $\mathrm{A} \beta_{25-35}$-stimulated cells. The experiment was performed in outside-out mode (Valenzuela et al., 2000) at $0 \mathrm{mV}$ membrane potential. Single-channel properties are closely related to the already described biophysical characteristics of CLIC1 chloride permeability (Tonini et al., 2000; Valenzuela et al., 2000). At this concentration, IAA-94 is a highly specific blocker of CLIC1 chloride current, according to previous studies using CHOtransfected cells (Valenzuela et al., 2000) and artificial membrane systems (Tulk et al., 2000, 2002; Warton et al., 2002). From these experiments, we obtained data to plot an $I-V$ relationship (Fig. $3 d$ ) from which we calculated single-channel conductances of $8.63 \pm 0.015 \mathrm{pS}$ and a current reversal potential of $-63 \mathrm{mV}$, corresponding to a chloride permeability in these experimental conditions. In Figure $3 e$, we show the histograms, with the statistics over a large number of experiments, of the probability to observe CLIC1 channel activity in cell-attached configuration. In the case of $A \beta$ stimulation, the probability to find at least one single channel was much greater than in any other experimental condition. It follows that the increased channel open probability associated with $\mathrm{A} \beta$ stimulation is probably attributable to both an increased number of functional channels on the plasma membrane and the prolongation of channel mean open time. This supports data described above that demonstrate increased CLIC1 protein on the plasma membrane in association with cell activation.

We experienced a serious problem performing whole-cell experiments to further support this evidence. CLIC1 is extremely sensitive to cytoplasmic washout, perhaps because it may move out of, as well as onto, membranes. This was also true in CLIC1transfected CHO cells used in our previous studies (Tonini et al.,

e Controls. c
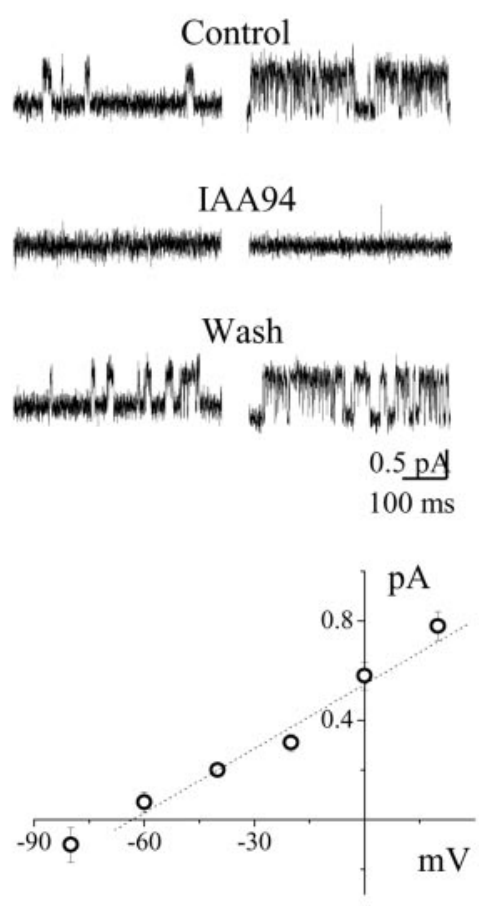

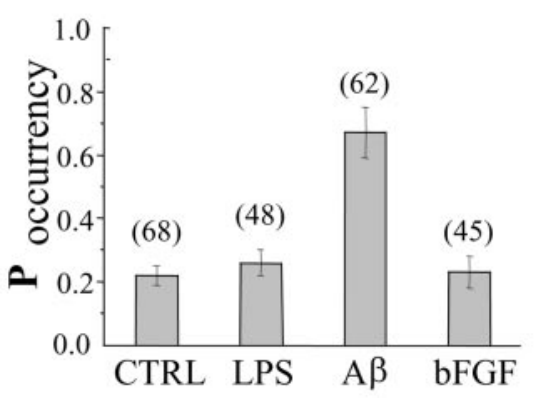

Figure 3. $A \beta$ stimulation alters $\mathrm{CLIC1}$ single-channel activity in BV-2 cells. $a$, Sample traces recorded in untreated BV- 2 cells (left) and in cells stimulated with $30 \mu \mathrm{M} \mathrm{A} \beta$ for $24 \mathrm{hr}$ (right) at $+20 \mathrm{mV}$ membrane potential. $b$, CLIC1 channels showed a fitted by the single-exponential decay functions (line). Controls, mean $\tau_{0}=4.3 \mathrm{msec}$, 273 openings; $A \beta$-stimulated, mean $\tau_{0}=$ $10.4 \mathrm{msec}, 537$ openings. C, Outside-out single-channel block by $10 \mu \mathrm{m}$ IAA-94 on both control and stimulated BV-2 cells. $d$ $015 \mathrm{pS}$ and a current reversal potential of $-63 \mathrm{mV}$. $e, A \beta_{25-35}$ at $30 \mu \mathrm{m}$, but not $1 \mu \mathrm{g} / \mathrm{ml} \mathrm{LPS}$ or $100 \mathrm{ng} / \mathrm{ml} \mathrm{bFGF}$ treatment increases the probability to record CLIC1 single-channel events on the cell membrane of BV- 2 cells after $24 \mathrm{hr}$ of stimulation. CTRL,

2000; Valenzuela et al., 2000). We also tried to use the perforatedpatch technique, but the majority of the current records appeared unstable.

\section{Blockade of CLIC1 inhibits microglial cell proliferation}

$\mathrm{A} \beta_{25-35}$ is known to modify microglial morphology, proliferation, and ability to produce potentially neurotoxic molecules. Additionally, a number of scientific reports suggest that the proliferation of microglia is dependent on the activity of ionic membrane currents, in particular on chloride conductances (Schlichter et al., 1996; Eder, 1998). To investigate the possible role of CLIC1 in the process of $A \beta$-mediated microglial proliferation, we used IAA-94 to test the influence of CLIC1 chloride conductance on the proliferation of microglial cells. IAA-94, used at concentrations $<50 \mu \mathrm{M}$, behaves as a specific CLIC1 chloride channel 


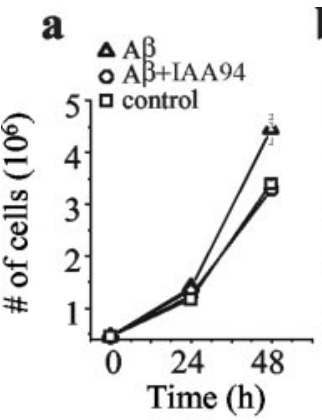

\section{b}

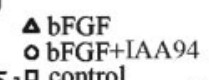

5 [ control
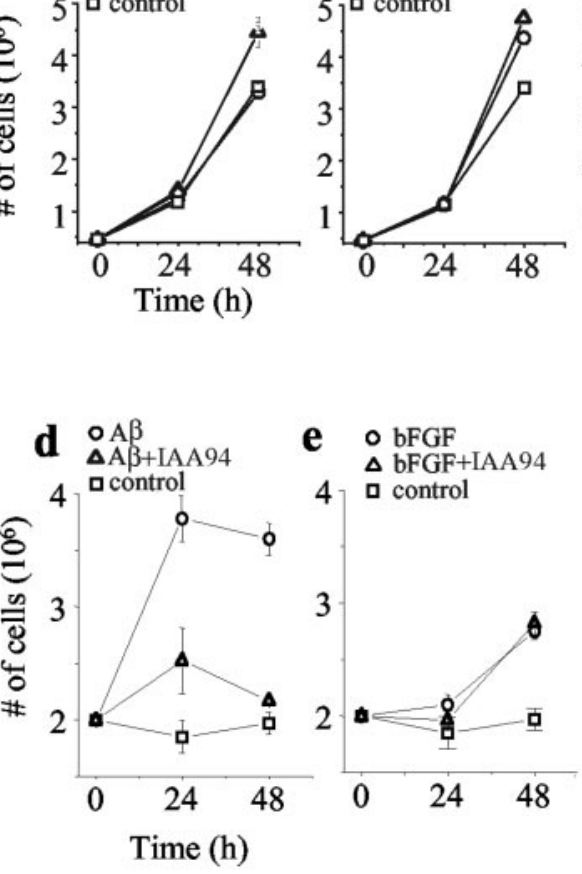

Figure 4. Effect of chloride channel blockers on the proliferation of microglia. BV-2 cells were treated with $30 \mu \mathrm{mA} \beta 25-35$ ( $a$ ) or $100 \mathrm{ng} / \mathrm{ml} \mathrm{bFGF}(b)$ alone or in combination with the CLIC1 channel blocker IAA-94 $(30 \mu \mathrm{m})$. Cells treated with IAA94 alone are shown in c. In d, rat primary microglia was stimulated with $30 \mu \mathrm{m} \mathrm{A} \beta_{25-35}$ alone and together with $30 \mu \mathrm{M}$ IAA-94. The same experiment but using bFGF $100 \mathrm{ng} / \mathrm{ml}$ is shown in e. Cell count was performed after 24 and $48 \mathrm{hr}$ of treatment. The experiments were repeated four times with similar results.

blocker. Figure 4 shows the effect of IAA-94 on cellular growth rate measured in the presence of $\mathrm{A}_{25-35}(a, d)$ and $\operatorname{bFGF}(b, e)$ in BV-2 cells $(a-c)$ and primary microglia $(d, e)$. Both $\mathrm{A} \beta_{25-35}$ and bFGF induced a mitogenic response in microglial cells, and IAA-94 inhibited $\mathrm{A} \beta$-induced microglial proliferation, although it did not seem to interfere with the proliferation of either bFGFtreated or control microglial cells.

\section{Blockade of CLIC1 inhibits neuronal toxicity induced by A $\boldsymbol{\beta}_{25-35}$-activated microglial cells}

As mentioned previously, $\mathrm{A} \beta_{25-35}$-dependent activation of microglia results in acquisition of a reactive phenotype with the production and secretion of proinflammatory products. Activated microglia is believed to influence the course of $\mathrm{AD}$ by accelerating the rate of neuronal death. On the basis of these observations, we investigated whether IAA-94 could be a neuroprotective agent. Neuronal survival was tested in the presence of $\mathrm{A} \beta_{25-35}$-stimulated primary rat microglia in two different cellular models: mixed neuronal-microglial cultures, in which microglial cells were seeded among cortical neurons, and neuronal-microglial cocultures, in which hippocampal neurons were cocultivated with microglial cells but were not in direct contact with them. Figure $5 a$ shows cortical neuronal cell viability determined by uptake and hydrolysis of fluorescein diacetate after $24 \mathrm{hr}$ of $\mathrm{A} \beta_{25-35}$ incubation. Negligible signs of damage were observed in primary neurons alone or in mixed neuronal-microglial cultures. In contrast, the $\mathrm{A} \beta_{25-35}$-activated microglia exerted a marked neurotoxic effect that was inhibited by simultaneous incubation with the CLIC1 chloride channel blocker IAA-94 (18 $\pm 2.3 \%$ of $\mathbf{a}$

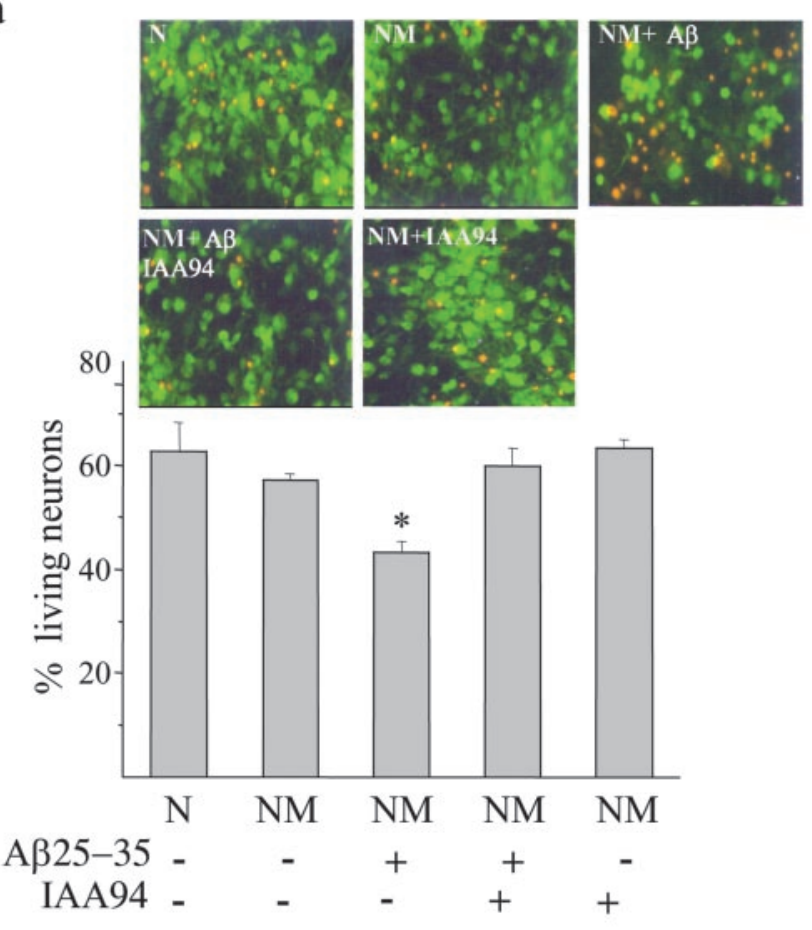

b
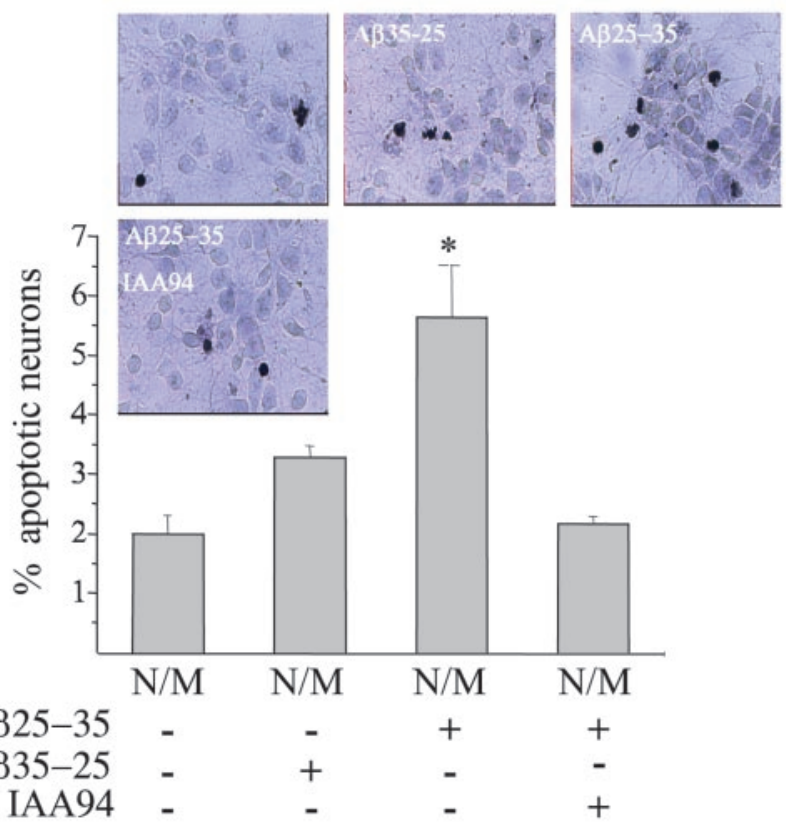

Figure 5. CLIC1 blockade protects neurons from microglia-mediated $A \beta$-induced neurotoxicity. $a$, Viability of cortical neurons determined by uptake and hydrolysis of fluorescein diacetate after $24 \mathrm{hr}$ of incubation with $30 \mu \mathrm{m} \mathrm{A} \beta$. The first two columns are data obtained from cortical neurons (N) and neurons plus microglial cells (NM). The combination of microglia and $\mathrm{A} \beta$ treatment exerted the highest neurotoxic effect (middle column), which was reversed by the simultaneous incubation with the CLIC1 chloride channel blocker IAA-94 (30 $\mu \mathrm{M})$. IAA-94, tested separately on nonstimulated mixed cultures, had no effects on neuronal survival. Histograms represent the means \pm SEM obtained from 12 different fields counted for each sample; ${ }^{*} p<0.001$ versus untreated mixed cultures and cultures treated with $A \beta$ in combination with IAA-94; ANOVA with Bonferroni-corrected $t$ test. $b$, The percentage of apoptotic neurons is shown in cocultures of hippocampal neurons and microglia (N/M) treated for $24 \mathrm{hr}$ with $30 \mu \mathrm{M}$ $A \beta$ or the correspondent reverse peptide alone or in combination with $30 \mu \mathrm{M}$ IAA-94. The percentage of apoptotic cells was calculated as the number of TUNEL-positive cells divided by the total cell number. Histograms represent the means \pm SEM; $n=3$ experiments; ${ }^{*} p<0.05$ versus controls (untreated cocultures or cultures treated with the reverse peptide $A \beta_{35-25}$ ) and A $\beta$ plus IAA-94; Mann-Whitney $U$ test. 


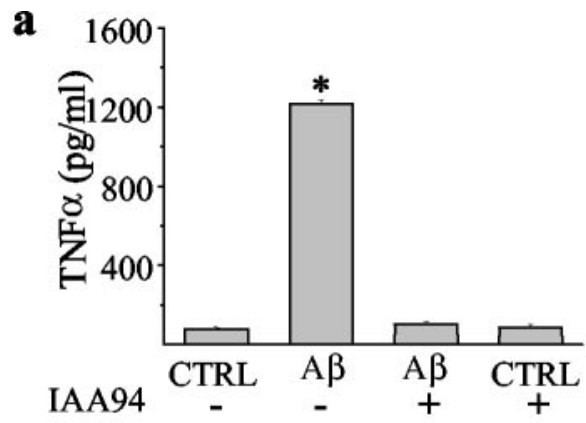

b

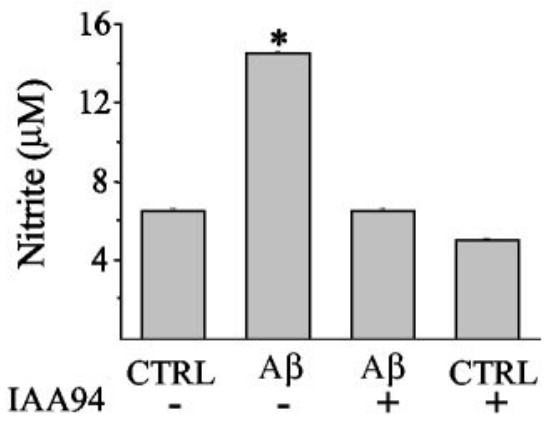

Figure 6. IAA-94 reverses the $A \beta_{25-35}$ induction of both TNF- $\alpha$ and nitric oxide release. Cocultures of hippocampal neurons and microglia were treated for $24 \mathrm{hr}$ with $30 \mu \mathrm{m} \mathrm{A \beta} 25-35$ alone or in combination with $30 \mu \mathrm{m} \mathrm{IAA-94}$. Conditioned media were collected and analyzed for TNF- $\alpha$ by ELISA ( $a$ ) and for nitrite levels using the Griess reaction $(b) .{ }^{*} p<0.001$ versus controls (CTRL) (untreated or IAA-94-treated cocultures) and A $\beta$ plus IAA-94; ANOVA with Bonferroni-corrected $t$ test. Data shown are means \pm SEM.

surviving rescue). IAA-94, tested separately on nonstimulated mixed cultures, had no effects on neuronal survival.

To confirm that the $\mathrm{A} \beta$-induced neurotoxicity was attributable to the microglial production of diffusible neurotoxic molecules, we used cocultures, in which neuronal cells were not in direct contact with the microglial cells (Fig. 5b). Neuronal apoptosis was measured by TUNEL after $24 \mathrm{hr}$. Neurons conditioned by $\mathrm{A} \beta$-treated microglia showed a clear increase in the number of TUNEL-labeled neuronal nuclei compared with control and reverse $A \beta_{35-25}$-stimulated cultures. As observed previously with the mixed neuronal-microglial cultures, IAA-94 was able to prevent the neurotoxicity generated by activated microglia (Fig. $5 b$ ). Control neuronal cultures transferred onto plates containing A $\beta$ but not the microglial monolayer did not show any increase in the number of apoptotic nuclei with respect to untreated cells (data not shown). However, our Western blot analysis of CLIC1 expression in purified hippocampal primary neurons shows only an almost undetectable band corresponding to CLIC1 molecular weight. Together, these results indicate that, in our experimental conditions, IAA-94 possibly acts by blocking microglial activation but not affecting directly neuronal survival.

\section{Blockade of CLIC1 inhibits $\mathrm{A} \boldsymbol{\beta}_{25-35}$-activated microglial cell production of TNF- $\alpha$ and nitrite}

To address the question of how IAA-94 might protect neurons from $\mathrm{A} \beta$-mediated neurotoxicity, we measured the production of TNF- $\alpha$ (Fig. $6 a$ ) and $\mathrm{NO}_{2}{ }^{-}$(Fig. $6 b$ ), which are known to mediate neuronal toxicity (Araujo and Cotman, 1992; Meda et al., 1995; Casal et al., 2002). The results show that both TNF- $\alpha$ and $\mathrm{NO}_{2}{ }^{-}$release were upregulated by $\mathrm{A} \beta_{25-35}$. Furthermore, CLIC1 chloride channel blockers were able to prevent their release from microglial cells. This inhibition was observed not only
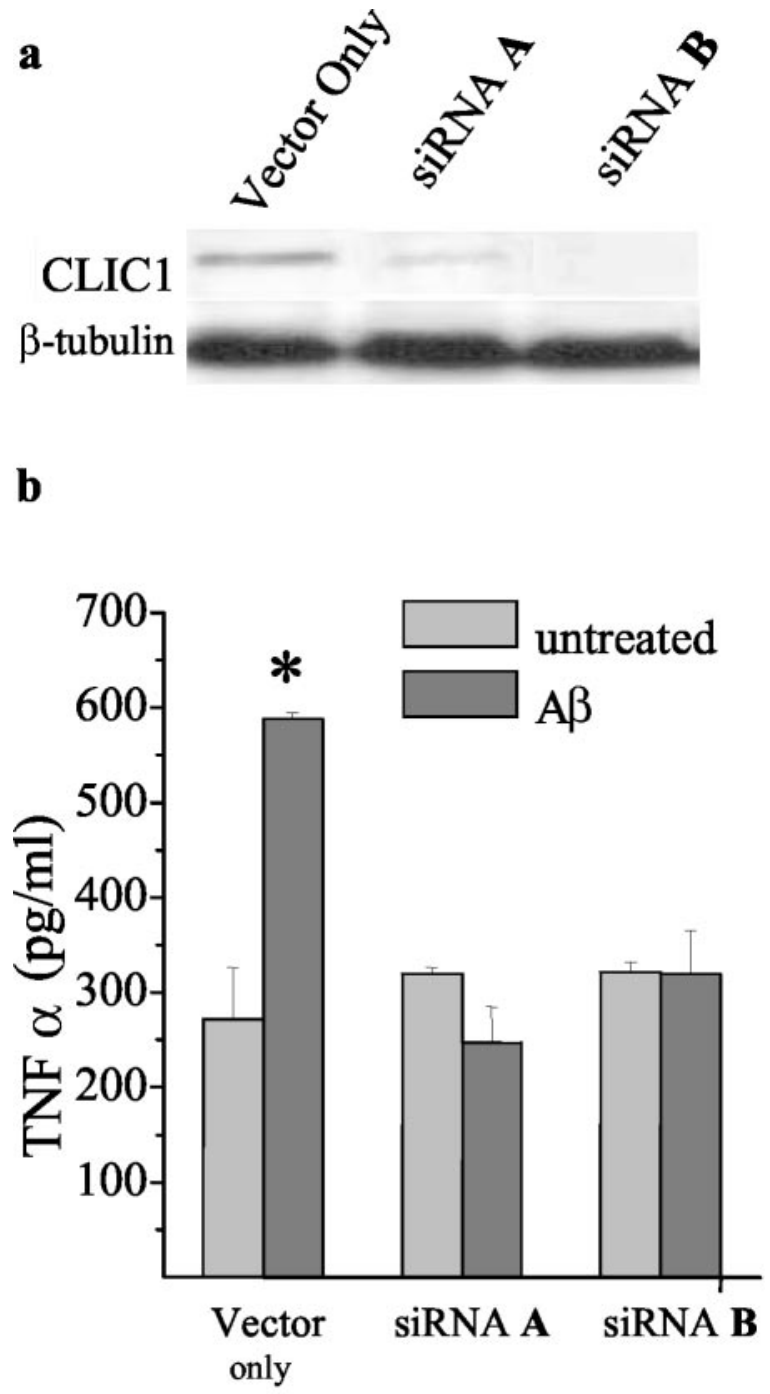

Figure 7. siRNAs inhibit TNF- $\alpha$ release in $A \beta_{25-35}$-stimulated BV-2 cells. BV-2 cells were transiently transfected with psiUb-clic 1 A or psiUb-clic1 B generating siRNA A or siRNA B. Western blot analysis of CLIC1 expresssion after $48 \mathrm{hr}$ of transfection with vector only or with siRNA A or siRNA B is shown in $a$. After $48 \mathrm{hr}$ of transfection, BV-2 cells were stimulated with $30 \mu \mathrm{m}$ $A \beta_{25-35}$ for $24 \mathrm{hr}$, the supernatants were collected, and TNF- $\alpha$ levels were measured by ELISA (b).

for IAA-94 (30 $\mu \mathrm{M})$ but also for niflumic acid (100 $\mu \mathrm{M})$, another CLIC1 blocker (data not shown).

RNA interference for CLIC1 reduces the production of TNF- $\alpha$ in $\mathrm{A} \boldsymbol{\beta}_{25-35}$-activated BV-2 cells

To demonstrate a functional role of CLIC1 and its involvement in $\mathrm{A} \beta$-induced microglial activation, we knocked down CLIC1 expression by a DNA vector-based RNA interference technique in which siRNAs are processed from short hairpin RNAs (shRNAs) (McManus and Sharp, 2002) (Dykxhoorn et al., 2003). In particular, we used a recently developed RNAi vector in which shRNAs are transcribed under the control of the polymerase II U1 promoter (M. A. Denti, A. Rosa, O. Sthandier, F. G. De Angelis, and I. Bozzoni, unpublished observation). As a functional assay of microglial activation, we measured the production of TNF- $\alpha$ after A $\beta$ stimulation (Giri et al., 2003; Meda et al., 1995). The psiUb-CLIC1 constructs encode siRNAs that target the regions of CLIC1 mRNA indicated in Materials and Methods. The 21nucleotide-long target sequences were chosen because they have 
no significant homology with other known murine genes, including the other members of the CLIC family. BV-2 cells were transfected with the control vector (psiUx) or with psiUb-clic 1 constructs. At $48 \mathrm{hr}$ after transfection, cells were stimulated with $\mathrm{A} \beta$ for $24 \mathrm{hr}$. All of the constructs reduce TNF- $\alpha$ release after $A \beta$ treatment. Figure $7 b$ shows the effects of the two more efficient constructs, which were able to completely prevent TNF- $\alpha$ release induced by A $\beta$ treatment.

\section{Discussion}

Alzheimer's disease is a severe debilitating disorder for which no satisfactory therapy is available. It is characterized by the presence of a prominent inflammatory response, and targeting this inflammatory response offers one potentially useful therapeutic strategy. Therapy of inflammatory processes generally, but especially those involving the CNS, are difficult, and new therapeutic targets are required. As a group, ion channels have been particularly useful therapeutic targets, especially for the development of drugs acting on the cardiovascular system. We believe that the CLIC1 ion channel may be such a potential target, and this paper provides substantial evidence to validate this concept.

CLIC1 was originally cloned on the basis of increased mRNA expression with macrophage activation. However, in this paper, we provide the first evidence for increase in CLIC1 protein associated with a disease-specific activation modality. Furthermore, not only is increased protein expressed (Fig. 1), but, in association with $\mathrm{A} \beta$ activation, CLIC1 has a higher probability of being present in the plasma membrane (Fig. $1 f$ ), in which it needs to be located to function as an ion channel. This is further confirmed by the presence of substantially increased plasma membrane CLIC1-related ion channel activity accompanying cell activation (Fig. 3). In addition, this increase in CLIC1 protein expression is specific to the $\mathrm{A} \beta$ peptide and is not associated with LPS of bFGF treatment, consistent with data indicating that CLIC1 is not an LPS-responsive gene (Valenzuela et al., 1997).

How CLIC1 is involved in the activation process of microglial cells, at present, is not clear. However, it is known that stimulation of microglia with $\mathrm{A} \beta$ fibrils results in the activation of several kinases and the mobilization of intracellular calcium (Kalaria, 1999; Bamberger and Landreth, 2001). It is possible that the overall increase of CLIC1 protein attributable to $\mathrm{A} \beta$ stimulation promotes movement of CLIC1 onto the plasma membrane. In addition, changes in CLIC1 channel kinetics observed after $\mathrm{A} \beta$ treatment may be attributable to phosphorylation of some of the several putative target sites on CLIC1 (Valenzuela et al., 1997) and/or calcium mobilization. Both of these mechanisms could contribute to a marked increase of functional expression of CLIC1 chloride conductance.

The consequence of activation of microglial cells by $\mathrm{A} \beta$ peptide is the release of diffusible toxic substances that result in neuronal death. It is likely that at least two contributing molecules are TNF- $\alpha$ and nitric oxide, both of which are released as part of this activation process. Importantly, inhibition of CLIC1 conductance by the selective CLIC1 ion channel blocker IAA-94 (Figs. 5, 6) virtually completely abrogates both the release of TNF- $\alpha$ and nitrite production, as well as the consequent neurotoxicity. These results were reinforced using the RNA interference procedure, in which specific small RNAs for CLIC1 mRNA were able to completely inhibit TNF- $\alpha$ release after $\mathrm{A} \beta$ stimulation (Fig. 7). Both of these experimental procedures strongly support the involvement of CLIC1 protein during A $\beta$ microglial activation.

In conclusion, it appears that the inhibition of $\mathrm{A} \beta$-induced microglial activation could be reached by a reduction of CLIC1 function. How blocking a chloride channel inhibits the activation process is unknown. One speculative possibility is that calcium mobilization requires an influx of chloride ions to act as counterions. Limiting chloride entry into the cell may limit calcium mobilization and hence cell activation. Whatever the mechanism, it appears highly likely that blocking CLIC1 limits microglial activation and release of neurotoxic substances. Although an element of nonspecificity is always possible with pharmacological blockers, the sum total of information provided argues strongly that CLIC1 is involved in the $\mathrm{A} \beta$-induced microglial cell activation and that blocking this ion channel serves to diminish it. We suggest that CLIC1 should be considered as a therapeutic target for Alzheimer's disease and, indeed, other inflammatory diseases.

\section{References}

Apparsundaram S, Schroeter S, Giovanetti E, Blakely RD (1998) Acute regulation of norepinephrine transport. II. PKC-modulated surface expression of human norepinephrine transporter proteins. J Pharmacol Exp Ther 287:744-751.

Araujo DM, Cotman CW (1992) Beta-amyloid stimulates glial cells in vitro to produce growth factors that accumulate in senile plaques in Alzheimer's disease. Brain Res 569:141-145.

Bamberger ME, Landreth GE (2001) Microglial interaction with beta-amyloid: implications for the pathogenesis of Alzheimer's disease. Microsc Res Tech 54:59-70.

Barger SW, Harmon AD (1997) Microglial activation by Alzheimer amyloid precursor protein and modulation by apolipoprotein E. Nature 388:878-881.

Benveniste EN, Nguyen VT, O’Keefe GM (2001) Immunological aspects of microglia: relevance to Alzheimer's disease. Neurochem Int 39:381-391.

Bezzi P, Carmignoto G, Pasti L, Vesce S, Rossi D, Rizzini BL, Pozzan T, Volterra A (1998) Prostaglandins stimulate calcium-dependent glutamate release in astrocytes. Nature 391:281-285.

Brewer GJ, Torricelli JR, Evege EK, Price PJ (1993) Optimized survival of hippocampal neurons in B27-supplemented Neurobasal, a new serumfree medium combination. J Neurosci Res 35:567-576.

Casal C, Serratosa J, Tusell JM (2002) Relationship between beta-AP peptide aggregation and microglial activation. Brain Res 928:76-84.

Combs CK, Karlo JC, Kao SC, Landreth GE (2001) $\beta$-Amyloid stimulation of microglia and monocytes results in TNF $\alpha$-dependent expression of inducible nitric oxide synthase and neuronal apoptosis. J Neurosci 21:1179-1188.

Dykxhoorn DM, Novina CD, Sharp PA (2003) Killing the messenger: short RNAs that silence gene expression. Nat Rev Mol Cell Biol 4:457-467.

Eder C (1998) Ion channels in microglia (brain macrophages). Am J Physiol 275:C327-C342.

Egensperger R, Kosel S, von Eitzen U, Graeber MB (1998) Microglial activation in Alzheimer disease: association with APOE genotype. Brain Pathol 8:439-447.

Giri RK, Selvaraj SK, Kalra VK (2003) Amyloid peptide-induced cytokine and chemokine expression in THP-1 monocytes is blocked by small inhibitory RNA duplexes for early growth response-1 messenger RNA. J Immunol 170:5281-5294.

Glenner GG, Wong CW (1984) Alzheimer's disease: initial report of the purification and characterization of a novel cerebrovascular amyloid protein. Biochem Biophys Res Commun 120:885-890.

Goslin K, Banker G (1990) Rapid changes in the distribution of GAP-43 correlate with the expression of neuronal polarity during normal development and under experimental conditions. J Cell Biol 110:1319-1331.

Itagaki S, McGeer PL, Akiyama H, Zhu S, Selkoe D (1989) Relationship of microglia and astrocytes to amyloid deposits of Alzheimer disease. J Neuroimmunol 24:173-182.

Kalaria RN (1999) Microglia and Alzheimer's disease. Curr Opin Hematol 6:15-24.

Malchiodi-Albedi F, Domenici MR, Paradisi S, Bernardo A, Ajmone-Cat MA, Minghetti L (2001) Astrocytes contribute to neuronal impairment in beta A toxicity increasing apoptosis in rat hippocampal neurons. Glia 34:68-72.

McGeer EG, McGeer PL (1997) The role of the immune system in neurodegenerative disorders. Mov Disord 12:855-858.

McGeer EG, McGeer PL (1998) The importance of inflammatory mechanisms in Alzheimer disease. Exp Gerontol 33:371-378. 
McGeer PL, Kawamata T, Walker DG, Akiyama H, Tooyama I, McGeer EG (1993) Microglia in degenerative neurological disease [review]. Glia 7:84-92.

McGeer PL, Walker DG, Akiyama H, Yasuhara O, McGeer EG (1994) Involvement of microglia in Alzheimer's disease. Neuropathol Appl Neurobiol 20:191-192.

McManus MT, Sharp PA (2002) Gene silencing in mammals by small interfering RNAs. Nat Rev Genet 3:737-747.

Meda L, Cassatella MA, Szendrei GI, Otvos LJ, Baron P, Villalba M, Ferrari D, Rossi F (1995) Activation of microglial cells by beta-amyloid protein and interferon-gamma. Nature 374:647-650.

Schlichter LC, Sakellaropoulos G, Ballyk B, Pennefather PS, Phipps DJ (1996) Properties of $\mathrm{K}^{+}$and $\mathrm{Cl}^{-}$channels and their involvement in proliferation of rat microglial cells. Glia 17:225-366.

Styren SD, Kamboh MI, DeKosky ST (1998) Expression of differential immune factors in temporal cortex and cerebellum: the role of alpha-1antichymotrypsin, apolipoprotein E, and reactive glia in the progression of Alzheimer's disease. J Comp Neurol 396:511-520.

Tonini R, Ferroni A, Valenzuela SM, Warton K, Campbell TJ, Breit SN, Mazzanti M (2000) Functional characterization of the NCC27 nuclear protein in stable transfected cho-k1 cells. FASEB J 14:1171-1178.
Tulk BM, Schlesinger PH, Kapadia SA, Edwards JC (2000) CLIC-1 functions as a chloride channel when expressed and purified from bacteria. J Biol Chem 275:26986-26993.

Tulk BM, Kapadia S, Edwards JC (2002) CLIC1 inserts from the aqueous phase into phospholipid membranes, where it functions as an anion channel. Am J Physiol Cell Physiol 282:C1103-C1112.

Valenzuela S, Martin D, Por S, Robbins J, Bootcov M, Schofield P, Campbell T, Breit S (1997) Molecular cloning and expression of a chloride ion channel of cell nuclei. J Biol Chem 272:12575-12582.

Valenzuela SM, Mazzanti M, Tonini R, Qiu MR, Warton K, Musgrove EA, Campbell TJ, Breit SN (2000) The nuclear chloride ion channel NCC27 is involved in regulation of the cell cycle. J Physiol (Lond) 529:541-552.

Warton K, Tonini R, Fairlie WD, Matthews JM, Valenzuela SM, Qiu MR, Wu WM, Pankhurst S, Bauskin AR, Harrop SJ, Campbell TJ, Curmi PMG, Breit SN, Mazzanti M (2002) Recombinant CLIC1 (NCC27) assembles in lipid bilayers via a $\mathrm{pH}$-dependent two-state process to form chloride ion channels with identical characteristics to those observed in Chinese hamster ovary cells expressing CLIC1. J Biol Chem 277:26003-26011.

Yankner BA, Duffy LK, Kirschner DA (1990) Neurotrophic and neurotoxic effects of amyloid beta protein: reversal by tachykinin neuropeptides. Science 250:279-282. 